Rayia J Al-Naimi ${ }^{1}$ BDS, MSc (Lect)

Faraed D Salman' BDS, MSc (Lect)

Faiz A Al-Sultan 2 BSc, MSc (Assist Lect)

\section{Diabetic dental problems in Mosul City}

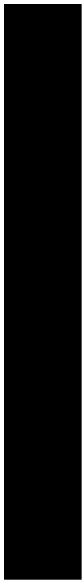

1Dept of Pedod, Orthod and Prev Dent

College of Dentistry, University of Mosul

2Department of Oral and Maxillofacial Surgery

College of Dentistry, University of Mosul

\begin{abstract}
The aim of this study was to evaluate dental problems of diabetic adult patients in Mosul City center, to find if there is any variation between age and sex groups and to determine the periodontal treatment needs of the patients.

A sample of 194 adult diabetic patients (90 males, 104 females) divided into 6 age groups were examined using plaque and gingival indices by Löe and Silness (1967), Ramfjord calculus index (1959) and Community Periodontal Index of Treatment Needs (CPITN) (1997).

The results showed that the mean plaque and gingival indices for the total sample were increasing with age with highly statistically significant difference with no sex variation. Concerning Ramfjord calculus index, calculus became the most prevalent with very high means for 20-29 years old and above for both sexes, CPITN revealed that healthy sextants exhibited a very low mean of 0.8 for the youngest age group, bleeding on probing was highest in this age group with a mean of 3.4, pockets of 4-5 $\mathrm{mm}$ appeared at age 20-29 years and it increases with increasing age.

The results revealed that the total sam-ple needed oral hygiene instruction $(100 \%)$, while prophylaxis was needed in $55.56-100 \%$, surgical intervention and complex care were needed for old ages.
\end{abstract}

Key Words: Diabetes, Community Periodontal Index of Treatment Needs, periodontal health.

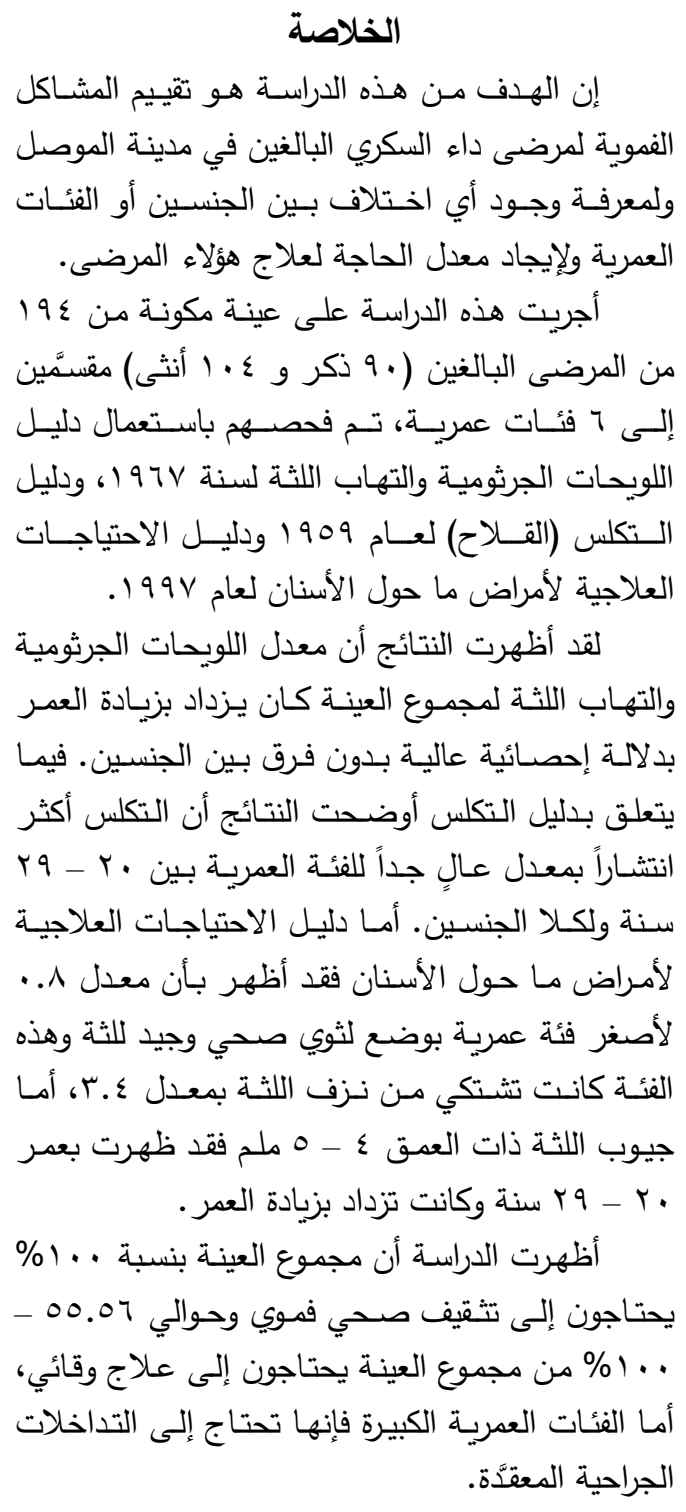




\section{INTRODUCTION}

Oral health complications associated with diabetes that may be encountered by dental practitioners may include xerostomia, tooth loss, gingivitis, periodontitis in addition to soft tissue lesions of the tongue and mucosa. ${ }^{(1-3)}$

Diabetes mellitus is a chronic metabolic disorder that affects nearly 100 million people worldwide. ${ }^{(4)}$

Diabetes is commonly categorized as insulin dependent diabetes mellitus (IDDM) and non-insulin dependent diabetes mellitus (NIDDM), about $10-20 \%$ of all diabetic patients are insulin dependent or type 1 . These patients usually have rapid onset of symptoms and are characterized by a virtually inability to produce insulin, nearly $90 \%$ of type 1 patients are diagnosed before the age of 21 years. Noninsulin dependent diabetes mellitus is most common and is characterized by slow onset of symptoms usually after 40 years of age. ${ }^{(5)}$

When compared to healthy subjects, gingival and periodontal diseases are often reported to be more prevalent in IDDM and NIDDM. ${ }^{(3,6,7)}$

The aim of the current study was to describe the most common dental problems in diabetic patients in Mosul City.

\section{MATERIALS AND METHODS}

The target population of the study was 194 patients attending for general treatment of diabetes at Al-Wafaa Center for the investigation and treatment of diabetic patients in Mosul City (10 individuals were IDDM and 184 were NIDDM). Because of the limited number of type 1 diabetes, they were all included with the same Table and they mostly were in the first age group.

Clinical examination was performed under natural daylight using sharp sickle shaped caries explorer, plane mouth mirrors and CPI probe. General information regarding name, age, sex were gathered from the patients in a special case sheet.

Plaque and gingival conditions were assessed according to Löe and Silness $1967,{ }^{(8)}$ Ramfjord calculus index $1959^{(9)}$ was used to determine calculus while the
Community Periodontal Index of Treatment Needs (CPITN) was used to determine the periodontal treatment needs of the patient. ${ }^{(10)}$ Teeth lost were also recorded with the exception of the third molars.

Data were analyzed using t-test; results were considered statistically significant when $p \leq 0.05$, and highly significant when $p \leq 0.01$.

\section{RESULTS}

Distribution of the sample by age and gender is shown in Table (1). The sample was composed of 194 patients (90 males and 104 females) distributed into 6 age groups.

Table (1): Distribution of the sample by age and gender

\begin{tabular}{cccc}
\hline Age & Male & Female & Total \\
\hline$<\mathbf{2 0}$ & 4 & 6 & 10 \\
$\mathbf{2 0}-\mathbf{2 9}$ & 2 & 4 & 6 \\
$\mathbf{3 0}-\mathbf{3 9}$ & 20 & 6 & 26 \\
$\mathbf{4 0}-\mathbf{4 9}$ & 40 & 34 & 74 \\
$\mathbf{5 0}-\mathbf{5 9}$ & 16 & 40 & 56 \\
$\mathbf{6 0}$ & 8 & 14 & 22 \\
\hline Total & 90 & 104 & 194 \\
\hline
\end{tabular}

The mean tooth loss per individual is shown in Table (2), which was increased with increasing age with a statistically significant age difference as there was no tooth loss for individuals under 20 years of age and it increased to more than 7 teeth for age groups over 60 years. Although the females showed slightly more tooth loss than males for all age groups, there was no statistically significant difference between them.

Table (3) displays the mean plaque, gingival and calculus indices for the total sample, the 3 indices were increasing with age with a highly statistically significant age difference $(p \leq 0.01)$ but no significant difference in mean plaque, gingival and calculus indices was found between males and females in the different age groups.

Table (4) illustrates the mean number of sextants for each stage of the disease for the sample. 
It could be seen that the healthy sextants exhibited a very low figure with a mean of only 0.8 for the youngest age group while it was negligible and absent in the oldest groups. Bleeding on probing was the most prevalent and highest mean in the young age group (3.4) and it became less as the age increased, while on the other hand calculus became the most prev- alent with very high means for age groups 20-29 years and above. Also pockets of 4$5 \mathrm{~mm}$ appeared at this age and increased with increasing age, pockets of $6 \mathrm{~mm}$ or more began to appear in age groups 30-39 years and above, while excluded sextants (having 2 or less teeth) appeared in the age group 40-49 years and increased with increasing age.

Table (2): Mean tooth loss per individual \pm standard deviation

\begin{tabular}{|c|c|c|c|}
\hline \multirow{2}{*}{$\begin{array}{c}\text { Age } \\
\text { Group }\end{array}$} & \multicolumn{3}{|c|}{$\begin{array}{c}\text { Gender } \\
(\text { Mean } \pm \text { Standard Deviation })\end{array}$} \\
\hline & Male & Female & Total \\
\hline$<20$ & $0 \pm 0$ & $0 \pm 0$ & $0 \pm 0$ \\
\hline 20-29 & $3 \pm 2.8$ & $3.5 \pm 2.1$ & $3.33 \pm 3.0$ \\
\hline 30-39 & $3.5 \pm 2.15$ & $3.2 \pm 2.7$ & $3.41 \pm 3.1$ \\
\hline 40-49 & $4.2 \pm 3.05$ & $4.3 \pm 3.6$ & $4.25 \pm 3.8$ \\
\hline $50-59$ & $5.7 \pm 3.8$ & $5.9 \pm 4.6$ & $5.74 \pm 4.4$ \\
\hline$\geq 60$ & $7.75 \pm 3.30$ & $8.5 \pm 3.39$ & $8.35 \pm 3.99$ \\
\hline
\end{tabular}

Table (3): Mean plaque, gingival and calculus indices for the groups

\begin{tabular}{|c|c|c|c|c|}
\hline \multirow{2}{*}{$\begin{array}{c}\text { Age } \\
\text { (Years) }\end{array}$} & \multirow{2}{*}{ Gender } & $\begin{array}{l}\text { Plaque } \\
\text { Index }\end{array}$ & $\begin{array}{c}\text { Gingival } \\
\text { Index }\end{array}$ & $\begin{array}{l}\text { Calculus } \\
\text { Index }\end{array}$ \\
\hline & & \multicolumn{3}{|c|}{ Mean \pm Standard Deviation } \\
\hline \multirow{3}{*}{$<\mathbf{2 0}$} & Male & $1 \pm 0.45$ & $1.03 \pm 0.35$ & $0.15 \pm 0.16$ \\
\hline & Female & $1.06+0.39$ & $1.26 \pm 0.27$ & $0.83+0.64$ \\
\hline & Total & $1.04 \pm 0.39$ & $1.16 \pm 0.29$ & $0.56 \pm 0.60$ \\
\hline \multirow{3}{*}{ 20-29 } & Male & $1.61 \pm 0.3$ & $1.5 \pm 0.21$ & $1.11 \pm 0.27$ \\
\hline & Female & $1.33 \pm 0.13$ & $1.56 \pm 0.06$ & $0.75+0.02$ \\
\hline & Total & $1.42+0.16$ & $1.54+0.27$ & $0.87+0.55$ \\
\hline \multirow{3}{*}{ 30-39 } & Male & $1.54 \pm 0.46$ & $1.49 \pm 0.34$ & $0.9 \pm 0.57$ \\
\hline & Female & $1.37 \pm 0.08$ & $1.35 \pm 0.25$ & $1.10 \pm 0.63$ \\
\hline & Total & $1.46 \pm 0.32$ & $1.42 \pm 0.4$ & $0.95 \pm 0.58$ \\
\hline \multirow{3}{*}{$40-49$} & Male & $1.41 \pm 0.21$ & $1.44 \pm 0.26$ & $0.79 \pm 0.44$ \\
\hline & Female & $1.49 \pm 0.28$ & $1.66 \pm 0.54$ & $1 \pm 0.52$ \\
\hline & Total & $1.44 \pm 0.15$ & $1.54 \pm 0.42$ & $0.9 \pm 0.49$ \\
\hline \multirow{3}{*}{$50-59$} & Male & $1.62 \pm 0.26$ & $1.52 \pm 0.12$ & $0.96 \pm 0.66$ \\
\hline & Female & $1.52 \pm 0.19$ & $1.5 \pm 0.20$ & $1.01 \pm 0.56$ \\
\hline & Total & $1.55 \pm 0.21$ & $1.51 \pm 0.18$ & $0.99 \pm 0.57$ \\
\hline \multirow{3}{*}{$\geq 60$} & Male & $1.53 \pm 0.21$ & $1.57 \pm 0.40$ & $0.90 \pm 0.41$ \\
\hline & Female & $1.56 \pm 0.14$ & $1.51 \pm 0.13$ & $1.01 \pm 0.20$ \\
\hline & Total & $1.60 \pm 0.18$ & $1.53 \pm 0.26$ & $0.97 \pm 0.30$ \\
\hline
\end{tabular}

Gender: Plaque Index: $\mathrm{t}=0.74, \mathrm{df}=5$, Not significant.

Gingival Index: $\mathrm{t}=0.78, \mathrm{df}=5$, Not significant.

Calculus Index: $\mathrm{t}=-1.087, \mathrm{df}=5$, Not significant

Age: Plaque Index: $\mathrm{t}=16.92, \mathrm{df}=5$, Significant

Gingival Index: $\mathrm{t}=22.30, \mathrm{df}=5$, Significant

Calculus Index: $t=10.53, d f=5$, Significant 
Table (4): Mean number of sextants for each stage of the disease

\begin{tabular}{|c|c|c|c|c|c|c|c|}
\hline $\begin{array}{c}\text { Age } \\
\text { (Years) }\end{array}$ & Gender & $\mathbf{0}$ & 1 & 2 & 3 & 4 & 5 \\
\hline \multirow{3}{*}{$<20$} & Male & 2 & 4 & & & & \\
\hline & Female & & 3 & 3 & & & \\
\hline & Total & 0.8 & 3.4 & 1.8 & & & \\
\hline \multirow{3}{*}{ 20-29 } & Male & & 1 & 5 & & & \\
\hline & Female & & 1.5 & 2.5 & 2 & & \\
\hline & Total & & 1.33 & 3.33 & 1.34 & & \\
\hline \multirow{3}{*}{ 30-39 } & Male & & 0.9 & 4 & 0.44 & 0.66 & \\
\hline & Female & & 2 & 3 & 1 & & \\
\hline & Total & & 1.17 & 3.75 & 0.58 & 0.5 & \\
\hline \multirow{3}{*}{$40-49$} & Male & 0.05 & 1.54 & 3.45 & 0.82 & & 0.14 \\
\hline & Female & 0.07 & 1.63 & 2.93 & 1.18 & 0.19 & \\
\hline & Total & 0.06 & 1.58 & 3.23 & 0.97 & 0.08 & 0.08 \\
\hline \multirow{3}{*}{$50-59$} & Male & 0.12 & 1.38 & 2.13 & 1.87 & & 0.5 \\
\hline & Female & & 1.15 & 2.7 & 1.4 & 0.5 & 0.25 \\
\hline & Total & 0.05 & 1.18 & 2.54 & 1.54 & 0.36 & 0.33 \\
\hline \multirow{3}{*}{$\geq 60$} & Male & & 0.25 & 4 & 1.25 & 0.25 & 0.25 \\
\hline & Female & & 0.43 & 2.86 & 1.28 & 0.29 & 1.14 \\
\hline & Total & & 0.36 & 3.27 & 1.27 & 0.27 & 0.83 \\
\hline \multicolumn{3}{|c|}{$\begin{array}{l}0=\text { Healthy } . \\
1=\text { Bleeding on probing. } \\
2=\text { Supra } \text { or sub- gingival } \\
3=\text { Pocket } 4-5 \mathrm{~mm} \text { deep. } \\
4=\text { Pocket } 6 \mathrm{~mm} \text { or more. } \\
5=\text { Excluded sextant. }\end{array}$} & lculus. & & & & \\
\hline
\end{tabular}

Table (5) shows the percentage of the mean number of sextants according to the gender for the total sample. Calculus was the most highest percentage and prevalent feature for both males and females in the sample, while females tended to have less healthy and more shallow pockets and excluded sextants compared to males.
Table (6) demonstrates the periodontal treatment needs expressed as percentages for the sample, the total sample needed oral hygiene instructions (100\%), prophylaxis was needed at a percentage between 55.56-100\%, while surgical intervention and complex care were needed for old age groups (40-49 years and above).

Table (5): Percentage of mean number of sextant according to the sex of total sample

\begin{tabular}{cccc}
\hline Sextant & Male & Female & Total \\
\hline Healthy & 6 & 0.2 & 3.2 \\
Bleeding & 25 & 27 & 26 \\
Calculus & 51.5 & 48 & 49.2 \\
Shallow Pockets & 12.5 & 20 & 16.2 \\
Deep Pockets & 2.6 & 1 & 2.1 \\
Excluded & 2.4 & 3.8 & 3.3 \\
\hline
\end{tabular}


Table (6): Periodontal treatment needs expressed as percentage

\begin{tabular}{|c|c|c|c|c|c|}
\hline $\begin{array}{c}\text { Age } \\
\text { (Years) }\end{array}$ & Gender & Healthy & $\begin{array}{c}\text { Oral Hygiene } \\
\text { Instruction }\end{array}$ & Prophylaxis & Surgery \\
\hline \multirow{2}{*}{$<20$} & Male & & 100 & 100 & \\
\hline & Female & & 100 & 100 & \\
\hline \multirow{2}{*}{ 20-29 } & Male & & 100 & 100 & \\
\hline & Female & & 100 & 100 & \\
\hline \multirow{2}{*}{ 30-39 } & Male & & 100 & 55.56 & \\
\hline & Female & & 100 & 66.67 & \\
\hline \multirow{2}{*}{$40-49$} & Male & & 100 & 100 & \\
\hline & Female & & 100 & 83.33 & 16.67 \\
\hline \multirow{2}{*}{$50-59$} & Male & & 100 & 100 & \\
\hline & Female & & 100 & 76.2 & 23.8 \\
\hline \multirow{2}{*}{$\geq 60$} & Male & & 100 & 75 & 25 \\
\hline & Female & & 100 & 85.7 & 14.3 \\
\hline
\end{tabular}

\section{DISCUSSION}

This is the first study in Mosul about some of the oral health problems of diabetic patients.

Results showed that there was a high tooth loss per individual which was increased with increasing age with a statistically significant age difference. This is in agreement with other studies. ${ }^{(6,11,12)}$ There was no significant difference in mean tooth loss for both genders; this contradicts the results of another study that found females to have more tooth loss than males. $^{(12)}$

The mean plaque, gingival and calculus indices were high and also increased with increasing age with a highly statistically significant age difference. These figures were much higher than that reported in another study, ${ }^{(6)}$ while no differences in the mean indices were found between males and females, compared to normal individuals. These indices were nearly the same as that reported in another study carried out in Mosul, ${ }^{(13)}$ but it contradicts the findings of a study that found diabetic patients had higher indices and more severe periodontal disease compared to normal individuals. ${ }^{(14)}$

The mean number of healthy sextants per person was nearly absent and was found mostly in the youngest age group. Elevated blood glucose with subsequent med- ical complications may be the common etiologic factor for the pathophysiology of dental disease or may be viewed as surrogates for poor health behaviours. As individuals became older bleeding tendency from the gingiva became less while the nu-mber of sextants with calculus and pockets increased, deep pockets of $6 \mathrm{~mm}$ and over were found in age group 30-39 years and older ages, while excluded sextants (less than 2 teeth present) began to appear at 40-49 years of age and older groups, although it has been reported that the prevalence of edentulism is higher in diab-etic population compared to normal indiv-iduals ${ }^{(15)}$ but these results are similar to the findings of another study carried out on normal individuals in a rural area in Nine-vah, with the exception that the former study tended to have more healthier sex-tants than this one for all age groups. ${ }^{(16)}$

The percentage of the mean number of sextants according to gender for the total sample shows that males tended to have a more healthier gingiva with less shallow pockets compared to females that had less healthy, more shallow pockets and excluded sextants compared to males.

The periodontal treatment needs were massive, the group needed oral hygiene instructions at a percentage of $100 \%$ regardless of their age groups. Scaling and 
polishing was needed at a percentage between $55.56-100 \%$, while surgical intervention was needed in 40-49 years and above and mostly in females compared to males. This result contradicts the results of other studies on normal individuals which found that females tended to have a more healthier and less pocket involvement so needed less treatment when compared to males. ${ }^{(17,18)}$

The consequences of periodontal disease and subsequent tooth loss are not only important considerations for the quality of life of a diabetic patient but may signifi-cantly impact an overall health by compro-mising a patient's ability to maintain a healthy diet and proper glycemic cont-rol. ${ }^{(19)}$ Therefore, an efficient dental health care programme should be constructed in the center to achieve an acceptable stand-ard of oral hygiene. Also dental education programme for these individuals is an essential activity for promoting their oral health and reducing oral disease in diabetic patients.

\section{CONCLUSIONS}

This study has shown that dental and periodontal problems are common and severe in diabetic patients. Further studies are needed to compare diabetics to age and sex matched controls in order to determine the role of diabetes in the development of these problems; but even this study shows that these problems are serious enough to warrant more attention in patient care, oral hygiene need to be emphasized in diabetic education and regular examination of the oral cavity should be included in the follow-up of patients.

\section{REFERENCES}

1) Galii D, Mordechi F, Garfunkel AA. Oral and dental complications asso-ciated with diabetes and their treat-ment. Compend Continuing Educ Dent. 1984; 15: 496-508.

2) May OA. Management of the diabetic dental patient. Quintessence Int 1990; 21: 491-494.

3) Löe H. Periodontal disease: The sixth complication of diabetes mellitus. Diabetes Care. 1993; 16: 329-334.

4) Harris MI. Diabetes in America / National Diabetes Data Group. NIH Publication. 1995.

5) The Expert Committee on the Diag-nosis and Classification of Diabetes Mellitus. Report of the expert comm-ittee of the diagnosis and classification of diabetes mellitus. Diabetes Care. 1997; 20: 1183-1197.

6) Bacic M, Cigar I, Granic M, Plancak D, Sutalo J. Dental status in a group of diabetic patients. Community Dent Oral Epidemiol. 1989; 17: 313316.

7) Oliver RC, Tervonen $\mathrm{T}$. Periodontitis and tooth loss: Comparing diabetics with the general population. J Am Dent Assoc. 1993; 124: 71-76.

8) Löe $H$. The gingival index, the plaque index and the retention index. $J$ Peri-odontol. 1967; 38: 610-616.

9) Ramfjord SP. Indices for prevalence and incidence of periodontal disease. $J$ Periodontol. 1959; 30: 51-56.

10) World Health Organization. Oral Hea-lth Survey, Basic Methods. $4^{\text {th }}$ ed. Wo-rld Health Organization. Geneva, Sw-itzerland. 1997.

11) Emrich LJ, Sholssman M, Genco RJ. Periodontal disease in non insulin dep-endent diabetes mellitus. $J$ Period-ontol. 1991; 62: 123-131.

12) Yohannes B, Surur SA. A study of dental problems in diabetic patients. Ethiop Med J. 1992; 30: 95-103.

13) Al-Sayagh GhDh. Prevalence and severity of root surface caries in rel-ation to periodontal status and edu-cational levels in adult population in Mosul City, Iraq. MSc thesis. Uni-versity of Mosul9. College of Dent-istry. 2000.

14) Raylander $H$, Ramberg $P$, Blohme G, Lindhe J. Prevalence of periodontal disease in young diabetics. J Clin Per-iodontol. 1986; 14: 3843.

15) Moore PA, Weyant RJ, 
Mongelluzzo MB. Type 1 diabetes mellitus and oral health: Assessment of tooth loss and edentulism. J Dent Public Health. 1998; 58: 135-142.

16) Khamrco TY. Assessment of periodontal disease using the CPITN In-dex in a rural population in Ninevah, Iraq. East Mediterr Hlth J. 1999; 5(3): 549-555.

17) Ghali RF. Oral health status and treatment needs among students of

Received: $15 / 3 / 2004$
Baghdad University. MSc thesis. Uni-versity of Baghdad. College of Dent-istry. 1989.

18) Al-Beiruti N, Tayfour MT, Poulos W. Oral health status of students in Syrian Arab Republic. East Mediterr Hlth J. 1996; 2: 304-310.

19) Joshipura KJ, Willett WC, Douglass $\mathrm{CW}$. The impact of edentulous-ness on food and nutrient intake. J Am Dent Assoc. 1996; 127: 459-467.

Accepted for Publication: 11/9/2004 